\title{
NO MEIO DA APRENDIZAGEM COLABORATIVA E DO TREINAMENTO COOPERATIVO ${ }^{1}$
}

\author{
IN THE MIDDLE OF COLLABORATIVE LEARNING AND \\ COOPERATIVE TRAINING ${ }^{1}$
}

\author{
Jairit Garavit ${ }^{2}$ \\ https://orcid.org/0000-0003-1976-9891
}

1. ¿Este produto é o resultado do trabalho árduo de uma de suas Linhas de Pesquisa do projeto "Como deve pesquisar em Educação virtual e a distância?" do ano de 2021, realizada com Membros de forma interdisciplinar e interinstitucional (Professores - Alunos) da Pesquisa Seedbed: Sistemas Integrados de Gestão "Integradoss" Anexados ao GrupLAC: SIGCIENTY da Universidade Nacional Aberta e a Distância UNAD.

2. Engenheiro Industrial, Especialista em Educação Superior e à Distância, Mestre em Sistemas Integrados de Gestão HSEQ-RSC, Revisor de Pares da Elsevier, Revisor de Pares da Publons Academy e Advisor \& Peer Rewiever de Mendeley, Editor de Currículo em Revistas Acadêmicas - Minciencias. Líder da Seedbed de Pesquisa "Integradoss" e nomeado Professor Pesquisador da Escola de Ciências Básicas, Tecnologias e Engenharia ECBTI. Zona Caribenha, na Universidade Nacional Aberta e a Distância - UNAD. Email institucional Jairit.Garavit@unad.edu.co

Projeto de Pesquisa: ¿Cómo pesquisar em Educação virtual e a distância? 
Resumo: A corrente pedagógica sócio-construtivista considera que o aluno constrói seu conhecimento de forma mais efetiva durante o trabalho em grupo, durante o qual os demais integrantes do grupo devem discutir sua perspectiva de formação. $\mathrm{O}$ treinamento cooperativo e o treinamento colaborativo se enquadram nessa estrutura conceitual. A abordagem pedagógica experimental adotada neste estudo visa medir a sua eficácia, em termos do benefício da formação, conhecimento, autonomia e avanço do pensamento crítico, através do estudo comparativo de uma população de segundo ano: metade trabalhava em modo cooperativo ou colaborativo ; o outro de acordo com um método clássico de ensino. Os ganhos em termos de autonomia obtidos pelo trabalho colaborativo têm sido amplamente demonstrados.

Palavras chave: Educação mediada, treinamento cooperativo, estágios, treinamento colaborativo.

Abstract: The socio-constructivist pedagogical current considers that the student builds their knowledge more effectively during group work, during which the other members of the group must argue their perspective of formation. Cooperative training and collaborative training fit into this conceptual framework. The experimental pedagogical approach adopted in this study aims to measure its effectiveness, in terms of the benefit of training, knowledge, autonomy and advancement of critical thinking, through the comparative study of a secondyear population: half worked in the modality cooperative or collaborative; the other according to a classical teaching method. The gains in terms of autonomy obtained by collaborative work have been widely demonstrated.

Key Words: Mediated Education, Cooperative Training, Learning, Collaborative Training.

\section{Introdução}

Essa noção do apagamento do professor, levada ao extremo neste capítulo, o desafio do professor, o lugar que ele deve ocupar dentro da classe. Além disso, isso implica a noção de autonomia do aluno no contexto da sua formação, cuja importância é agora sublinhada nos

currículos escolares. Essa perspectiva de ensino em que o professor deixa de ocupar o lugar central está cada vez mais sendo posta em prática hoje. Muitas vezes está associada ao trabalho em grupo, na modalidade projeto, e ressalta a importância para o aluno de saber se comunicar com os outros. No âmbito deste estudo, estaremos interessados em modalidades particulares de aprendizagem em grupo: treinamento cooperativo e treinamento colaborativo. Procurará estudar em que condições e em que medida estes métodos de trabalho podem permitir tanto melhorar a aquisição de conhecimentos como desenvolver as competências sociais necessárias ao aluno, ao seu próprio desenvolvimento, aos seus estudos e ao seu futuro. vida profissional, numa perspectiva de autonomia. 
Inicialmente, será realizada uma investigação da bibliografia com a ambição de propor um referencial científico para este estudo. As diferentes correntes de ensino serão descritas, incluindo aquelas que dão um lugar importante para o trabalho em grupo. Em seguida, duas abordagens específicas para o trabalho em grupo serão definidas. Métodos para implementar esses tipos de aprendizagem serão apresentados. Posteriormente, será explicado o problema do estudo, bem como as hipóteses adotadas. A seguir, será descrito o método utilizado no arcabouço do estudo, bem como os resultados obtidos, que serão discutidos na parte final desta revisão de pesquisa.

\section{Treinamento em grupo: Cooperativa e Colaborativa}

\section{Streams de ensino}

As ciências da educação têm seus fundamentos teóricos, entre outros, na psicologia, sociologia, filosofia e ciências cognitivas. Nos modelos de Kozanitis (2005), o ensino e a aprendizagem podem ser agrupados em quatro correntes, que partem dessas diferentes disciplinas: a corrente comportamental (ou comportamentalista), a corrente cognitivista, a corrente construtivista e a corrente sócio-construtivista. A Tabela 1 abaixo apresenta uma visão geral desses diferentes fluxos.

Tabela 1.

Representação esquemática das principais tendências teóricas

\begin{tabular}{|c|c|c|c|c|}
\hline Atual & Construtivista & Parceiro construtivista & Cognitivo & Behaviorista \\
\hline Ensine, é ... & $\begin{array}{l}\text { Organize as situações } \\
\text { Aprendizagem propícia } \\
\text { ao diálogo para provocar } \\
\text { e resolver conflitos } \\
\text { sociocognitivos. }\end{array}$ & $\begin{array}{l}\text { Oferecer situações de } \\
\text { obstáculo que } \\
\text { possibilitem o } \\
\text { desenvolvimento de } \\
\text { representações } \\
\text { adequado do mundo. }\end{array}$ & $\begin{array}{c}\text { Presente } \\
\text { em formação } \\
\text { de uma maneira } \\
\text { estruturada, } \\
\text { hierárquico, } \\
\text { dedutivo. }\end{array}$ & $\begin{array}{l}\text { Estimule, crie e } \\
\text { fortalecer } \\
\text { comportamentos } \\
\text { observável } \\
\text { apropriado. }\end{array}$ \\
\hline $\begin{array}{c}\text { Aprender é } \\
\ldots\end{array}$ & $\begin{array}{c}\text { Co-construir o seu } \\
\text { Conhecimento em } \\
\text { enfrentar suas ações nas } \\
\text { dos outros. }\end{array}$ & $\begin{array}{l}\text { Construa e organize seu } \\
\text { conhecimento por meio } \\
\text { de sua ação limpa. }\end{array}$ & $\begin{array}{l}\text { Tratar e comprar } \\
\text { Informação de } \\
\text { notícias } \\
\text { de forma } \\
\text { organizada. }\end{array}$ & $\begin{array}{c}\text { Associado, por } \\
\text { condicionamento, } \\
\text { uma recompensa } \\
\text { para uma resposta } \\
\text { específico. }\end{array}$ \\
\hline $\begin{array}{l}\text { Métodos } \\
\text { educacional } \\
\text { apropriado }\end{array}$ & $\begin{array}{l}\text { Aprendizagem por meio } \\
\text { de projetos, discussões, } \\
\text { exercícios, trabalho. }\end{array}$ & $\begin{array}{c}\text { Aprendizagem por } \\
\text { problemas estudo aberto } \\
\text { dos casos. }\end{array}$ & $\begin{array}{l}\text { Mestre exposto, } \\
\text { resolução de } \\
\text { problemas fechada. }\end{array}$ & $\begin{array}{l}\text { Programa de auto- } \\
\text { estudo } \\
\text { assistido por } \\
\text { computador. }\end{array}$ \\
\hline
\end{tabular}

Garavit, J. 2021. 
O Behaviorismo, cujos fundamentos teóricos vêm do pensamento de Aristóteles, se interessa pelo estudo de comportamentos observáveis e mensuráveis e considera a mente como uma caixa preta. Esse termo surgiu no início do século 20, introduzido pelo psicólogo americano James Watson (Kozanitis, 2005). De acordo com essa corrente que dominou a psicologia americana até a década de 1950, o aprendizado é considerado uma modificação duradoura do comportamento resultante de um determinado treinamento (teoria estímuloresposta). Assim, quatro mecanismos permitem atuar no comportamento de aprendizagem:

- Dois mecanismos favorecem a reprodução do comportamento desejado, Trabalhar e estudar diligentemente: reforço positivo (adição de um estímulo motivador. Ex: a boa nota obtida reforça o comportamento de estudar diligentemente) e reforço negativo (retirada de um estímulo aversivo (ex. Para evitar uma atividade que o aluno não goste (como conversar, desde que alcance determinado resultado, irá estimulá-lo a trabalhar).

- Dois mecanismos, por outro lado, visam acabar com um comportamento que interferiria na aprendizagem: extinção (ausência de reforço positivo ou negativo. Ex: aluno cujo vizinho está conversando e o impede de fazer o curso, ignora a tagarelice , esperando essa cessação, devido à desatenção) e punição (adição de um estímulo aversivo).

É, portanto, uma clássica relação professor-aluno, baseada na previsão e controle do comportamento de aprendizagem individual por meio de esquemas que relacionam estímulos e reações (David, 2015). Na década de 1960, entretanto, certos experimentos mostraram os limites dessa teoria transmissiva passiva, orientada para o professor e controlada, da qual muitos autores se afastaram.

\section{A noção cognitivista}

Cognitivismo, do latim cognitio, que significa conhecimento, está interessado em conhecimento, memória, percepção e raciocínio. Essa corrente se desenvolveu em oposição ao behaviorismo e é apresentada em várias versões.

Em uma primeira versão, da qual Ausubel é um dos principais proponentes, a mente humana é considerada um sistema de processamento de informações. Um ensino baseado na comunicação de informações pelo professor pode ser eficaz, graças ao fenômeno da ancoragem, se integrar novos conhecimentos aos já dominados pelo aluno. Baseia-se, em particular, no princípio da diferenciação progressiva, que hoje parece óbvio porque é adotado

por muitos professores, segundo os quais as ideias gerais são apresentadas primeiro, antes de anexar informações cujo nível de detalhe vai aumentando gradualmente (Kozanitis, 2005). 
Numa segunda versão, com base na psicologia cognitiva, o aprendiz é considerado um membro vivo no decorrer da aprendizagem, no sentido de que implementa diferentes estratégias de aprendizagem, que são a contrapartida da estratégia de ensino do professor. A apropriação gradual e efetiva de estratégias mentais (estratégias cognitivas e metacognitivas) é considerada necessária para um processo de aprendizagem estruturado (Kozanitis, 2005). Assim, o aluno estabelece estratégias cognitivas relacionadas aos processos de memorização, compreensão, etc. Em seguida, analisa sua forma de pensar, trabalhar e avalia sua eficácia

para melhorá-la: trata-se de metacognição. É eficaz se for apresentado aos alunos como um meio necessário para atingir os objetivos do treinamento. A seguir,

\section{A noção construtivista}

Junto com o behaviorismo, desenvolveu-se o construtivismo, que se preocupa tanto com o processo de aprendizagem quanto com a natureza do conhecimento, estando os dois intimamente ligados. Segundo essa corrente derivada do pensamento de Sócrates, o aprendiz constrói sua realidade a partir de sua própria experiência. Portanto, o conhecimento está relacionado com aquele que sabe. Jean Piaget fundamenta sua teoria neste conceito e considera que qualquer abordagem educacional deve levar em conta esse processo progressivo de reconstrução na origem de sua base de conhecimento, durante o qual o indivíduo, livre de qualquer condicionamento, se apropria do mundo que o circunda. .

Em algumas ocasiões, Piaget especificou que o conflito entre vários elementos cognitivos, em uma mesma pessoa, lhe permite reorganizar seu conhecimento. Portanto, (Baudrit, 2007). Eu assimilo uma definição no ambiente físico e social, as situações de trabalho em grupo que promovem o embate de ideias, permitem esta sucessão de desestruturação e reestruturação cognitiva, encorajam-nos a reexaminar, rever e justificar os nossos próprios conhecimentos.

\section{A noção sócio-construtivista}

Em parte derivada do construtivismo, essa teoria enfatiza a dimensão relacional da aprendizagem. De fato, o construtivismo social considera que o aluno aprende comparando suas ideias com as de outros. Os três componentes essenciais deste modo de aprendizagem são, portanto, os seguintes:

- O aluno (dimensão construtivista que descreve o sujeito da aprendizagem).

- Os outros alunos e o professor (dimensão - parceiro).

- As situações e objetos de aprendizagem, que constituem o conteúdo do ensino. (dimensão interativa do ambiente).

Segundo Kozanitis (2005) e Vygotsky, fica demonstrado o papel fundamental que as interações sociais desempenham no desenvolvimento da cognição e, portanto, destaca-se de 
Piaget. A resolução de um conflito sócio-cognitivo, devido à descentralização que provoca no aprendiz em relação ao seu próprio ponto de vista, permite que este gere um progresso cognitivo. Em seguida, o professor coloca o aluno no centro de sua ação e promove o processo de interação. No entanto, outros autores, como Alain Baudrit (2007), consideram que também para Piaget, utilizo a noção de conflito sociocognitivo e que ele ocupa um lugar central, conforme mencionado no parágrafo anterior. Portanto, o trabalho em grupo aparece em várias escolas de pensamento, e em particular no sócio-construtivismo, como um importante instrumento para o avanço da aprendizagem. É nisso que nos concentraremos a seguir.

\section{Equipe de trabalho}

Philippe Meirieu (2010) define o grupo, na pedagogia escolar, como constituído por relações plurais de troca, articuladas em um contato com o dado e como o real, eliminando total ou parcialmente a autoridade do líder do grupo. Esta concepção de trabalho em grupo considera, portanto, que a educação deve ser realizada por meio de um grupo de indivíduos que interagem, a partir de situações específicas, e nas quais o professor se coloca a serviço do processo coletivo. Na verdade, portanto, não exerce mais autoridade e poder sobre os alunos como é o caso em uma concepção mais tradicional de ensino, do tipo palestra.

Do ponto de vista prático, diferentes tipos de agrupamentos são possíveis: turma inteira, classe média, grupos de 4, 3 ou 2 alunos. Já Peeters (2005) considera que a noção de grupo só se aplica a subconjuntos compostos por no mínimo 4 alunos, pois é a partir desse número que o número de links supera o número de pessoas. Na verdade, o número de links aumenta mais rápido do que o número de alunos:

- Laços interpessoais: cada aluno pode se relacionar não apenas entre si, mas também com cada subgrupo (casal, trios, quartetos).

- Links intragrupo: cada subgrupo pode construir um relacionamento com os outros.

Esse elevado número de possibilidades de troca estimula o aprendizado com as contribuições do conflito sociocognitivo, ao oferecer a este último múltiplas oportunidades de expressão. Os métodos de implementação do trabalho em grupo são muito numerosos e variam de acordo com os objetivos pretendidos (grupos de descoberta, aprofundamento de um aspecto de uma questão, grupo de confronto para provocar um afastamento das perspetivas iniciais, grupos de assimilação, reformulação dos conhecimentos que acabamos de apresentar). Vamos nos concentrar em dois deles: cooperativo e colaborativo. 


\section{Abordagens particulares para o trabalho em grupo Treinamento cooperativo}

Alain Baudrit utiliza a definição de treinamento ou aprendizagem cooperativa proposta pela Johnson \& Johnson, que a assimila para trabalhar em pequenos grupos onde um objetivo comum permite otimizar a aprendizagem de cada pessoa. Assim, postula-se que a atividade coletiva orientada na mesma direção, em direção a um objetivo compartilhado por todos, pode beneficiar cada membro do grupo para suas aquisições (Baudrit, 2007b). Isso requer vários recursos:

- Heterogeneidade em grupos:Os grupos são formados por pessoas de dois sexos, com habilidades ou experiências diferentes, e cujas filiações sociais ou culturais também podem ser diferentes. Essa heterogeneidade visa promover o intercâmbio entre os alunos, para promover a interatividade.

- Interdependência:Os alunos em grupos cooperativos só devem ser capazes de atingir seus objetivos de aprendizagem se outros alunos em seu grupo atingirem os seus. Portanto, é necessário distribuir as tarefas entre os diferentes membros dos grupos para que eles coordenem suas respectivas atividades, produção coletiva resultante da associação do trabalho de cada um, segundo uma lógica de montagem.

- Empoderamento individual:cada um contribui para a atividade comum, cada um tem uma parte do trabalho a fazer. Portanto, um fracasso individual inevitavelmente tem consequências no nível da realização coletiva. A vocação da aprendizagem cooperativa é promover os alunos, melhorar seu nível educacional.

\section{Treinamento colaborativo}

Treinamento ou aprendizagem colaborativa pode ser definida como uma atividade exploratória que os parceiros, em situação de alto grau de incerteza, são capazes de realizar em conjunto. Alain Baudrit (2007a) cita Roschelle e Teasley a esse respeito que veem na colaboração um dinamismo ordenado e sincronizado que resulta de uma tentativa contínua de construir e manter um pensamento cooperativo de um problema. Assim, a aprendizagem colaborativa pode ser implementada quando a atividade é de natureza coletiva e sim está relacionada com os chamados conhecimentos não fundamentais, ou seja, orientada para questões que requerem respostas incertas e ambíguas. Ao contrário da aprendizagem cooperativa, a aprendizagem colaborativa envolve principalmente:

- Negociação dentro do grupo para afirmar o ponto de vista.

- Um vaivém constante entre o pensamento individual e o coletivo. 
- Uma simetria entre os membros do grupo: o grupo tem o mesmo nível cognitivo e se considera igual entre si em seu status (os alunos que adotam o status de "líderes" ou "seguidores" alterariam esse equilíbrio).

Dependendo do contexto em que é implementada, a colaboração pode ser planejada segundo uma lógica de oposição, pensamento crítico, descoberta e inovação. Então falamos sobre colaboração contraditória. Ao contrário, pode se basear em uma lógica de coordenação de perspectivas e coconstrução de hipóteses para chegar a uma resposta comum. É uma colaboração construtiva. Essas características principais são fornecidas na sinopse da Tabela 2 a seguir.

mesa 2

\section{Colaboração Construtiva}

\begin{tabular}{|c|c|c|}
\hline Itens & Funcionalidade dos EUA & Orientação europeia \\
\hline Tipo de Colaboração & Colaboração construtiva. & Olaboração contraditória. \\
\hline Objetivo da Colaboração & $\begin{array}{c}\text { Encontre a (s) solução (ões) para } \\
\text { um problema, }\end{array}$ & $\begin{array}{c}\text { Encontre a lógica das tarefas de } \\
\text { descoberta coletiva. }\end{array}$ \\
\hline Atividades interativas & $\begin{array}{c}\text { Compartilhando o diálogo de } \\
\text { conhecimento entre pares. }\end{array}$ & $\begin{array}{c}\text { Confronto, Oposição de pontos } \\
\text { de vista. }\end{array}$ \\
\hline Processos Intersubjetivos & $\begin{array}{c}\text { Coordenação de perspectivas } \\
\text { entre parceiros. }\end{array}$ & $\begin{array}{c}\text { Raciocínio, reflexão para várias } \\
\text { pessoas. }\end{array}$ \\
\hline Processos Intrassubjetivos & Dotações por coordenação. & Desestabilização por oposição. \\
\hline Estágios Individuais & $\begin{array}{c}\text { Aquisição de conhecimento } \\
\text { pessoal }\end{array}$ & $\begin{array}{c}\text { Revisão de conhecimento } \\
\text { individual }\end{array}$ \\
\hline
\end{tabular}

Garavit, J. 2021

Em todos os casos, a ênfase está na troca entre os membros do grupo e na justificação da perspectiva dos outros dentro do grupo. Essas trocas capacitam as pessoas e visam mais aprender a viver juntos do que trabalhar juntos. O objetivo aqui está menos focado no progresso acadêmico do que em reunir os alunos, reuni-los e responsabilizá-los. A formação colaborativa baseia-se, portanto, no princípio do conflito sócio-cognitivo descrito nas seções anteriores e nas ideias de Piaget na medida em que este último considerou que as situações de trabalho colaborativo incentivavam os pares a desfocar, adotando perspectivas diferentes da sua e que o fato de enfrentar um ponto de vista diferente do seu dá origem a um choque de ideias que o incentiva a reconsiderar, reveja e justifique seu próprio conhecimento. (Baudrit, 2007c). O interesse da formação colaborativa reside nos benefícios sociais que dela podem derivar os alunos, ou seja, a capacidade de comunicar, partilhar ideias e exercitar o pensamento crítico, desenvolvendo a autonomia num funcionamento grupal mais livre. 


\section{Paralelo de treinamento cooperativo e colaborativo}

Em ambos os casos, se cooperativo ou colaborativo se refere ao trabalho em grupo, cujos membros buscam uma produção comum, e em que as interações e relações entre pares dentro do grupo são privilegiadas. Esses dois movimentos questionam a autoridade exercida pelo professor sobre os alunos em uma pedagogia tradicional, com transferência de autoridade para o grupo (coletivo estudantil), parcial no âmbito da formação cooperativa e mais completa para a colaborativa. (Baudrit, 2007c). Assim, em um quadro colaborativo, o professor fica em segundo plano e encaminha todas as questões para o grupo. ao passo que, em um contexto cooperativo, ele se move de um grupo para outro, observa interações, ouve conversas e intervém quando julgado útil.

O funcionamento do grupo é muito mais estruturado na formação cooperativa, devido à já mencionada necessidade de interdependência. Os alunos preparam-se para esta atividade coletiva (sensibilização para a ajuda mútua, partilha de papéis, etc.), o que não acontece na formação colaborativa, onde o grupo é muito mais livre. Baudrit (2007b) considera assim que A interação entre os pensamentos individuais e coletivos parece ser para a formação colaborativa o que parece ser a interdependência das conquistas entre eles para a formação cooperativa.

Tabela 3:

Aspectos comparativos entre: o cooperativo e o colaborativo.

\begin{tabular}{|c|c|c|}
\hline Critérios distintivos. & Aprendizado cooperativo. & Aprendizado colaborativo. \\
\hline Interações de troca. & $\begin{array}{c}\text { Estruturas (princípio da } \\
\text { interdependência). }\end{array}$ & $\begin{array}{c}\text { Não estruturado (Parrage, } \\
\text { compartilhamento de } \\
\text { conhecimento). }\end{array}$ \\
\hline Controle máximo. & Reel (Grupo de Observação). & Baixa (autonomia do aluno). \\
\hline Responsabilidade dos alunos. & Garabtie por interdependência. & Incerto (a critério de Cahun). \\
\hline Equidade entre os alunos. & $\begin{array}{c}\text { Impossível (natureza heterogênea } \\
\text { dos grupos). }\end{array}$ & $\begin{array}{c}\text { Imporbable (Organização gratuita } \\
\text { de grupos). }\end{array}$ \\
\hline Funções desempenhadas pelos & Risco de especialização. & $\begin{array}{c}\text { Risco de colapso. } \\
\text { alunos. }\end{array}$ \\
\hline Aprendizagem dirigida. & $\begin{array}{c}\text { Conhecimentos fundamentais } \\
\text { ligados às diferentes atividades } \\
\text { escolares. }\end{array}$ & $\begin{array}{c}\text { Conhecimento não fundamental: } \\
\text { pensamento crítico, raciocínio, } \\
\text { descoberta coletiva. }\end{array}$ \\
\hline
\end{tabular}

\section{Garavit, J. 2021.}

Em relação aos objetivos perseguidos, a cooperativa constituiria uma primeira etapa que visa estabelecer aprendizagens fundamentais, depois a colaborativa uma segunda, que permitiria avançar em conhecimentos não fundamentais, promovendo o exercício do livre 
julgamento. A Tabela 3 abaixo apresenta os principais critérios distintivos dos dois tipos de abordagem.

\section{Desafios e limites das formações cooperativas e colaborativas}

Estes dois métodos de aprendizagem baseiam-se em trocas entre pares, que no coletivo dos processos permitem criar dentro da turma e dos grupos um ambiente descontraído, de confiança, favorável à aprendizagem, mesmo que a confiança entre os alunos seja mais limitada no que se refere ao transmissão de conhecimentos (espontaneamente, os alunos confiam mais no professor nesta área). A partir de algumas perspectivas das aquisições esperadas para os alunos, a formação cooperativa permite uma estruturação eficiente do conhecimento, numa lógica de montagem (cada aluno domina uma parte do todo) enquanto a formação colaborativa permite o desenvolvimento de significado crítico no aluno, competência científica importante, numa lógica de compartilhamento e busca de consenso (cada um contribui com seu conhecimento,

Os benefícios no ambiente da sala de aula também são benéficos para o professor. Essas abordagens cooperativas e colaborativas permitem que você desempenhe um papel diferente dentro do grupo de classe. $O$ professor segue assim uma forma de pensar diferente para a preparação das sessões, nomeadamente numa abordagem colaborativa, onde parte da recuperação da informação é transferida para os alunos. Ele mesmo realiza pesquisas para construir sua própria produção, que pode eventualmente servir de referência para os alunos.

Por fim, a relação aluno-professor também se beneficia desses métodos, na medida em que promovem a democracia, permitem o estabelecimento de uma relação de cooperação entre alunos e professor, bem como a coconstrução. Além dos benefícios que podem ser extraídos dessas abordagens pedagógicas específicas, uma série de limites podem, no entanto, ser observados.

\section{Delimitações}

A formação cooperativa apresenta risco de especialização dos integrantes do grupo (os alunos só podem se interessar por sua parte, sem se esforçar para se apropriar daqueles que foram tratados por outrem). Além disso, quando há forte heterogeneidade no nível educacional dos alunos dentro dos grupos, os melhores tendem a desempenhar o papel de especialistas, o que não favorece a aprendizagem dos alunos mais fracos, aos quais é atribuído um papel inferior no cumprimento do comum tarefa (Baudrit, 2005). Para evitar essa armadilha, outra estratégia é favorecer a formação de grupos de afinidade. O risco dessa segunda estratégia deriva da fusão. Meirieu (1996 a) identifica quando os membros do grupo priorizam a qualidade de seus relacionamentos em detrimento da eficácia de seu trabalho. 
Em resumo, Como evoca Baudrit (2005): excessivamente qualificados, os alunos têm dificuldade em jogar o jogo da atividade coletiva, consideram seus colegas de trabalho como iguais, venham em seu auxílio se necessário. Muito próximos um do outro, eles podem se afastar das tarefas que têm de fazer.

No treinamento colaborativo, ele tem outras limitações. Devido à liberdade que permanece no funcionamento do grupo e na esperada produção coletiva, cujas características não são especificadas pelo professor, alguns alunos podem investir muito e outros muito menos. Portanto, as aquisições em termos de competências e conhecimentos não são garantidas e dependem mais da responsabilidade e atitude de cada aluno.

Finalmente, como em qualquer prática de aprendizagem em grupo, o uso de treinamento cooperativo e colaborativo deve ser feito com cautela. $\mathrm{Na}$ verdade, como evoca Meirieu (2010b), a prática exclusiva do grupo apresenta o risco de aprisionar o indivíduo em um modo único de apropriação do conhecimento, talvez muito fecundo, mas que poderia, a longo prazo, dissuadi-lo de empreender individual. investigações devido à sua conta. Portanto, a formação cooperativa e colaborativa não deve ser utilizada como única modalidade de trabalho para alunos por longos períodos, mas deve ser oferecida como modalidades de trabalho possíveis em temas bem focados, alternando com outras abordagens pedagógicas que requerem e valorizam o investimento. .

\section{Métodos de implementação de treinamento cooperativo e colaborativo Web 2.0}

A Internet é uma ferramenta que se presta particularmente bem ao trabalho colaborativo. O que se denomina Web 2.0, segundo expressão lançada por Tim O'reilly em 2004, é determinado pelas intervenções dos internautas na produção e publicação, portanto, na troca de conteúdo online. As interfaces permitem que os usuários interajam tanto com o conteúdo das páginas quanto entre si (Carrefour Educación, 2015). Esta colaboração é facilitada em particular por certas aplicações Web 2.0, como Wikis (Wikipedia, Wikimedia, Wiki mini, etc.), cujo sistema de gerenciamento de conteúdo permite que as páginas sejam modificadas por todos os usuários, que assim participam da escrita. conteúdo das páginas.

Estas aplicações acessíveis ao público em geral podem ser reinvestidas de forma útil num quadro educacional, com ferramentas mais específicas, como editores de texto colaborativos, como o Framapad, que também permitem que vários utilizadores escrevam o mesmo texto à distância, identificando cada utilizador. cor. Assim, vemos a construção gradativa de uma produção comum, para a qual todos possam contribuir, sincronicamente ou não, oferecendo agilidade na realização de projetos educacionais. Este novo modo de organização do material cria assim as condições que permitem aos alunos desenvolver propostas sem restrições. 
Portanto, é propício à produção intelectual livre (SUMPUTH \& FOURCADE, 2013), conforme definido no contexto do trabalho colaborativo.

\section{Cara a cara (cara a cara)}

Um método para implementar a aprendizagem cooperativa: o quebra-cabeça. O treinamento cooperativo pode ser implementado de diferentes maneiras (pares, grupos, modo de quebra-cabeça). Elliot Aronson é um dos promotores do sistema educacional. Quebracabeça, que viu a luz a partir de 1971, e a que Alain Baudrit (2009) alude, Já que, a operação é grupal e assimilada ao início do quebra-cabeça. Por exemplo, uma unidade de ensino é dividida em tantas partes quantos forem os alunos do grupo. Desta forma, cada um recebe uma parte que deve estudar e depois ensiná-la aos colegas. Desta forma, as respectivas contribuições dos diferentes membros do grupo permitem estudar a unidade didática de forma relativamente exaustiva.

Portanto, inicialmente, os grupos de membros são definidos: cada grupo de membros deve produzir um resumo. Em seguida, dentro desses grupos, cada aluno será designado a uma área de especialização, para a qual realizarão pesquisas dentro de um grupo de pesquisa (ou grupo de especialistas). No final da fase de pesquisa, os especialistas retornam ao seu grupo inicial para preparar a síntese, expondo aos demais membros do grupo os resultados que os especialistas alcançaram. Esse tipo de abordagem funciona bem em grandes tópicos, que não podem ser resolvidos individualmente, pelo menos em um limite de tempo limitado, como uma sessão de aula. Cabe ao professor estabelecer um clima de confiança e trocas, por isso deve levar em consideração os comportamentos sociais observados.

\section{Vários métodos de implementação}

Os métodos para implementar em treinamento cooperativo e colaborativo são variados. Seu sucesso dependerá de sua adaptação à cultura do país em que essas modalidades são aplicadas. Assim, em muitos países, a formação cooperativa pode assumir a forma de cooperação competitiva, que incentiva a competição entre os grupos a que pertencem, estimulada pela obtenção de recompensas pela melhor produção coletiva, o que, entretanto, apresenta o risco de limitar a cooperação. durante a fase de investigação. Essa abordagem também tem sido aplicada sem sucesso a estudantes latino-americanos, que estão mais em uma lógica de ajuda mútua do que competitiva (Baudrit, 2009).

A abordagem dos países do Oriente Médio é semelhante naquela parte do mundo. Uma vez que a formação cooperativa está mais próxima da formação colaborativa no sentido de que os professores dessas áreas orientais pouco intervêm e permitem que o grupo se organize de forma autônoma. A noção de coletividade e os valores da cooperação são de fato mais 
importantes para essas áreas ou países. Esses exemplos ilustram os vínculos complementares entre o treinamento cooperativo e colaborativo e destacam a necessidade de levar em consideração as tradições e os sistemas de valores específicos de cada país e de cada contexto local, a fim de adotar uma abordagem cooperativa ou colaborativa apropriada.

\section{Problemas dos tipos de treinamento}

Entre as diferentes correntes educacionais, o construtivismo social é aquele que dá lugar mais importante à intervenção de outrem no desenvolvimento do conhecimento. Assim, o conflito sócio-cognitivo permite que um aluno que trabalha em grupo mude sua abordagem e dê um passo atrás em suas concepções iniciais, obrigando-o a discutir o problema atribuído com os demais membros do grupo. Esse processo pode levar o aluno a questionar suas concepções iniciais e contribuir efetivamente para a construção de seu conhecimento.

Dois métodos de trabalho em grupo são enquadrados nesta estrutura de pensamento: treinamento cooperativo, baseado em grupos heterogêneos, interdependentes e com poder, e treinamento colaborativo, baseado em uma abordagem muito mais livre para o funcionamento do grupo. composto por membros considerados iguais entre si. O primeiro visa estabelecer a aprendizagem fundamental, enquanto o segundo visa ajudar o aluno a progredir e incentivá-lo a desenvolver o seu pensamento crítico, numa lógica de partilha e convivência.

O ensino de Ciências da Terra e Ciências da Vida no ensino secundário, em geral, segundo, em particular, é frequentemente implementado através do trabalho a pares. Portanto, é interessante nos perguntarmos sobre os seguintes pontos:

- O treinamento cooperativo realmente empodera os alunos? para melhor capacitar e assimilar o conhecimento abordado do que em um ambiente de trabalho de parceiro mais tradicional?

- O treinamento colaborativo também permite uma melhor participação do aluno e um maior interesse pelo conhecimento? Promove realmente o desenvolvimento da autonomia e do pensamento crítico?

A literatura sugere que este é realmente o caso. Isso é o que este capítulo tentará demonstrar. Assim, como parte de uma abordagem de pedagogia experimental, as seguintes hipóteses serão testadas:

- Alunos que trabalham cooperativamente em conceitos complexos e vastos assimilam conhecimentos melhor do que alunos que trabalham convencionalmente, em pares, nesses tópicos, a partir dos mesmos documentos. Assim, os primeiros estarão em 
melhor posição para efetivamente resgatar os conhecimentos adquiridos sobre esses temas e raciocinar, analisar resultados experimentais ou resolver um problema por meio da síntese de documentos. Portanto, esses alunos devem obter uma pontuação mais elevada nas correspondentes avaliações formativa e somativa.

- Em disciplinas que provocam o avanço do pensamento crítico, os alunos que trabalham de forma colaborativa tornam-se mais envolvidos na tarefa. $O$ funcionamento dos grupos colaborativos será muito autónomo e será ocasião de trocas construtivas, que permitirão aos alunos dar um passo atrás melhor do que os alunos que tratam a mesma matéria de forma tradicional. Nessas sessões, portanto, devemos observar comportamentos mais autônomos dos alunos no modo colaborativo, o que também deve resultar na obtenção de melhores notas durante a avaliação somativa, do que os alunos que trabalharam no modo clássico.

\section{Procedimentos}

O estudo foi realizado na Faculdade de Ciências da Saúde da Universidade Nacional Aberta e a Distância - UNAD - Colômbia. A escola tem 903 alunos, divididos entre tecnólogos e alunos de graduação (648 alunos profissionais) e (255 alunos tecnólogos), esta escola recebe alunos da cidade e de cidades vizinhas do Caribe. É um estabelecimento relativamente tranquilo, os alunos vêm de um ambiente sociocultural médio.

A população em que se focou o estudo é constituída por três segundas turmas gerais, cujo ensino ocorre ao longo do ano em turmas semestrais de cerca de quinze alunos, o que representa um total de 100 alunos para este estudo, incluindo 54 mulheres e 46 homens, 18 a 25 anos. Das três idades, seis mulheres e cinco homens estão um ano (ou mais) atrasados na escolaridade, ou seja, $11 \%$ da população; enquanto seis homens têm um ano de antecedência, ou $6 \%$ da população, ver tabela 4 abaixo.

\section{Tabela 4}

Características da população estudada, em número de alunos por categoria.

\begin{tabular}{|l|c|c|c|c|c|c|c|}
\hline \multirow{2}{*}{ Ano de Nascimento } & \multicolumn{2}{|c|}{ Estudantes femininas } & \multicolumn{3}{|c|}{ Estudantes masculinos } & \multirow{2}{*}{ Lições } \\
\cline { 2 - 9 } & $\mathbf{1 9 9 8}$ & $\mathbf{1 9 9 9}$ & $\begin{array}{c}\text { mil } \\
\text { novecentos } \\
\text { e noventa } \\
\text { e seis }\end{array}$ & $\mathbf{1 9 9 8}$ & $\mathbf{1 9 9 9}$ & $\mathbf{2 0 0 0}$ & Total \\
\hline Classe 2 & 2 & 18 & 0 & 2 & 9 & 2 & 33 \\
\hline Classe 6 & 1 & 16 & 0 & 0 & 13 & 3 & 3.4 \\
\hline Classe 7 & 3 & 14 & 1 & 2 & 13 & 1 & 3.4 \\
\hline \multicolumn{1}{|c|}{ Total. } & $\mathbf{6}$ & $\mathbf{4 8}$ & $\mathbf{1}$ & $\mathbf{4}$ & $\mathbf{3 5}$ & $\mathbf{6}$ & $\mathbf{1 0 0}$ \\
\hline
\end{tabular}

Garavit, J. 2021 
Como professor, ele era responsável pelo ensino de Ciências da Vida. para as classes 2 e 6 do ano, enquanto meu colega e tutor, um experiente professor $\mathrm{X}$, era responsável pelos alunos da $7^{\mathrm{a}}$ classe.

O nível escolar destes alunos no ECISA é um nível médio, sem distinção apreciável de resultados nem entre os sexos, nem entre as classes: a sua média anual no ECISA é 3,5 / 5,0, (igual ao teste 12/20) com notas ligeiramente superiores para alunos mais velhos, séries anteriores e mais baixas para alunos que já repetiram (ver Tabela 5 abaixo).

Tabela 5:

População média do ECISA estudada, por faixa etária (pontuação em 20 = 3,5).

\begin{tabular}{|c|c|c|c|c|c|}
\hline & \multicolumn{4}{|c|}{ Média anual no ECISA } & Total \\
\hline Nascimento & $\begin{array}{l}\text { mil novecentos } \\
\text { e noventa e seis }\end{array}$ & $\mathbf{1 9 9 8}$ & $\mathbf{1 9 9 9}$ & $\mathbf{2 0 0 0}$ & 11,8 \\
\hline & 0 & 12,1 & 11,8 & 11,2 & 12,3 \\
\hline & 0 & 11,0 & 12,3 & 12,9 & 12,0 \\
\hline & 11,5 & 9,6 & 12,3 & 14,5 & $\mathbf{1 2 , 0}$ \\
\hline
\end{tabular}

Garavit, J. 2021

\section{Formulário e procedimentos}

O estudo se concentrou na parte do Tópico do currículo do segundo ano, Corpo Humano e Saúde: Exercício Físico. Os conceitos abordados neste tópico prestaram-se bem a uma abordagem pedagógica cooperativa e colaborativa, desde uma perspectiva profunda de conhecimento (bastante complexa, que permite criar interdependência entre os alunos) e de atitudes (espírito crítico solicitado por um tema como o doping). Além disso, o facto de terem recorrido de perto durante várias sessões consecutivas a modalidades particulares de trabalho de grupo permite que os alunos se predisponham a este método de trabalho e realizem assim a preparação necessária para o trabalho cooperativo. A investigação foi formulada em etapas sucessivas, indicadas na Tabela 6 abaixo. 
Tabela 6:

Práticas para comitês de aprendizagem cobertos pelo estudo

\begin{tabular}{|c|c|c|c|}
\hline Compromisso & Modo de aprendizagem & Classe e Grupo & \# Alunos \\
\hline \multirow{2}{*}{$\begin{array}{l}\text { Regulamento PT de } \\
\text { pressão sanguínea }\end{array}$} & TP cooperativo & $\begin{array}{l}2^{\circ} 2 \text { Grupo A } \\
\text { 2o } 6 \text { Grupo A } \\
2^{\circ} 7 \text { Grupo A }\end{array}$ & 49 \\
\hline & $\begin{array}{l}\text { Trabalho prático clássico, } \\
\text { trabalho em pares }\end{array}$ & $\begin{array}{l}2^{\circ} 2 \text { Grupo B } \\
\text { 2o } 6 \text { Grupo B } \\
2^{\circ} 7 \text { Grupo B }\end{array}$ & 51 \\
\hline \multirow{2}{*}{$\begin{array}{c}\text { Sistema TP } \\
\text { músculo-articular }\end{array}$} & $\begin{array}{l}\text { Trabalho prático clássico, } \\
\text { trabalho em pares }\end{array}$ & $\begin{array}{l}2^{\circ} 2 \text { Grupo A } \\
\text { 2o } 6 \text { Grupo A } \\
2^{\circ} 7 \text { Grupo A }\end{array}$ & 49 \\
\hline & TP cooperativo & $\begin{array}{l}2^{\circ} 2 \text { Grupo B } \\
\text { 2o } 6 \text { Grupo B } \\
2^{\circ} 7 \text { Grupo B }\end{array}$ & 51 \\
\hline $\begin{array}{l}\text { Revisão do curso e } \\
\text { Teste formativo }\end{array}$ & $\begin{array}{c}\text { Avaliação nos dois laboratórios } \\
\text { anteriores }\end{array}$ & $\begin{array}{c}2^{\circ} 2 \text { Curso, em seguida, } \\
\text { Avalie. } 2^{\circ} 6 \mathrm{MCQ}, \text { em } \\
\text { seguida, indo para o } 2^{\circ} 7 \\
\text { Curso e, em seguida, Avalie. }\end{array}$ & 100 \\
\hline \multirow{2}{*}{ Doping TP } & Prática colaborativa & $\begin{array}{l}2^{\circ} 2 \text { Grupo A } \\
2 \text { o } 6 \text { Grupo A }\end{array}$ & 32 \\
\hline & $\begin{array}{l}\text { Trabalho prático clássico, } \\
\text { trabalho em pares }\end{array}$ & $\begin{array}{l}2^{\circ} 2 \text { Grupo B } \\
206 \text { Grupo B }\end{array}$ & 3.4 \\
\hline $\begin{array}{l}\text { Avaliação } \\
\text { somativa }\end{array}$ & Trabalho individual & $2^{\circ} 2,2^{\circ} 6$ e $2^{\circ} 7$ & 100 \\
\hline
\end{tabular}

Garavit, J. 2021

As duas primeiras sessões de trabalho prático visaram testar métodos de treino cooperativo (trabalho prático sobre a regulação nervosa da tensão arterial e trabalho prático sobre o sistema músculo-articular). Para essas sessões, em cada uma das três classes:

- Um grupo seguiu um treinamento tradicional, pois é realizado na maioria das vezes, ou seja, trabalha em duplas todos os conceitos abordados na sessão. Os alunos são convidados a refletir com seus vizinhos enquanto desenvolvem um registro individual por escrito.

- Enquanto o outro grupo trabalhou cooperativamente.

As modalidades foram invertidas de uma sessão para a outra: portanto, cada grupo realizava trabalhos práticos no modo cooperativo e o outro no modo tradicional. Como parte da pesquisa relacionada à minha tese, estabeleci uma metodologia do tipo pedagogia experimental. As folhas de atividades foram testadas primeiro na classe do meu tutor, ajustadas de acordo com as reações dos alunos ao suporte proposto e, em seguida, usadas nas minhas aulas. Em vez disso, primeiro testei o questionário de avaliação formativa em minhas aulas antes de oferecê-lo ao meu tutor. Esta abordagem iterativa tornou possível melhorar as 
planilhas em um pequeno e curto espaço de tempo, o que só é possível com um verdadeiro trabalho em equipe.

\section{Regulação da pressão arterial - Exemplo 1.}

Esta sessão tem como objetivo ajudar os alunos a compreender os mecanismos nervosos de regulação da pressão arterial. Essa noção é complexa para os alunos. Pareceu interessante tratá-lo em forma de trabalho cooperativo: formaram-se grupos domiciliares de 4 alunos, com o objetivo de produzir no final da sessão um diagrama funcional da regulação nervosa da pressão arterial, acompanhado de um texto explicativo respectivamente. para um caso de diminuição e um caso de aumento da pressão arterial. A interdependência dos membros do grupo é criada da seguinte forma: o grupo ao qual pertence é dividido em dois grupos de especialistas, alguns lidando com a percepção das variações da pressão arterial e a formação da mensagem nervosa sensível, outros são eles lidam com a formação de mensagens nervosas motoras, daí o papel dos nervos simpático e parassimpático. Uma fase de conferência permite que os dois pares compartilhem suas conclusões sobre os diferentes papéis dos jogadores no ciclo de regulação e completem o diagrama funcional.

Em seguida, cada dupla deve redigir o texto explicativo, um para o caso de queda de pressão, outro para o caso de aumento da pressão arterial, que exige que cada aluno analise todo o ciclo de regulação. Espera-se um registro individual escrito. para a folha de atividades. A execução deste trabalho prático de forma clássica baseou-se numa ficha de atividades semelhante, que reuniu as questões relacionadas com os especialistas dos dois temas. Portanto, cada par cuidava de todo o ciclo de regulação. Uma fase de conferência permite que os dois pares compartilhem suas conclusões sobre os diferentes papéis dos jogadores no ciclo de regulação e completem o diagrama funcional. Em seguida, cada par deve escrever o texto explicativo, um para o caso de queda de pressão, o outro para o caso de aumento da pressão arterial, o que exige que cada aluno analise todo o ciclo regulamentar. Espera-se um registro individual escrito.

A execução deste trabalho prático de forma clássica baseou-se numa ficha de atividades semelhante, que reuniu as questões relacionadas com os especialistas dos dois temas. Portanto, cada par cuidava de todo o ciclo de regulação. Uma fase de conferência permite que as duas duplas compartilhem suas conclusões sobre os diferentes papéis dos jogadores no ciclo de regulação e concluam as etapas colaborativas.

\section{Sistema músculo-articular - Exemplo 2.}

Esta sessão pretende fazer com que o aluno compreenda o funcionamento do sistema músculo-articular, as patologias a que este sistema pode estar sujeito, bem como os meios de 
prevenção que permitem evitar algumas dessas patologias. Várias variantes de laboratório cooperativo foram testadas:

- Para classes 6 e 7:alguns pares são especialistas em prevenção e ligamentos, outros são especialistas em tendões e patologias. Todos os casais realizam uma dissecção de asas de frango (alguns destacam ligamentos, outros tendões) e todos trabalham em documentos (gráficos e textos a serem analisados para prevenção; estudo de imagens médicas para patologias).

- Para a classe 2:alguns pares são especialistas em patologia e prevenção e trabalham apenas com documentos; enquanto os demais são especialistas no funcionamento do sistema músculo-articular, e realizam toda a dissecção da asa de frango. Eles devem identificar tendões, ligamentos, músculos e definir seus respectivos papéis.

Em todos os casos, os grupos a que pertencem deveriam realizar uma síntese em forma de diagrama a preencher (identificação dos tendões, ligamentos, músculos flexores e extensores) e tabela a preencher (papel, patologia e prevenção para cada elemento). O tipo de resultado esperado difere da sessão anterior, a fim de variar e permitir que os alunos tenham tempo para concluir todos os trabalhos da aula. Veja o Anexo 2 para a ficha de atividades.

\section{Sessão de treinamento colaborativo}

Um treinamento colaborativo é dedicado ao tema doping, com um grupo de teste e um conjunto de controles (trabalhando em pares) para cada uma das minhas aulas. Para tratar do assunto em sessão única (1h25), foi elaborada uma lista restrita de documentos que foi disponibilizada aos alunos, que também tinham acesso a computadores e Internet. Os documentos abrangem quatro áreas: substâncias dopantes (EPO, anabolizantes, etc.) e seu modo de ação, métodos de dopagem (autotransfusão e doping genético), os riscos associados à dopagem (riscos para a saúde, legais e financeiros) e, finalmente, sociais, econômica e ética (por que ficamos chapados?, teoria dos jogos). Os documentos fornecidos foram diagramas, tabelas e artigos de jornal.

Para grupos de aprendizagem colaborativa, as únicas instruções dadas foram as seguintes:

- Trabalhe em grupos de quatro alunos,

- No final da sessão, efetue uma produção coletiva relacionada com o doping, gratuita, mas que trate necessariamente dos quatro temas acima mencionados.

Deixo os alunos do grupo A da segunda turma, geralmente bem envolvidos, formarem livremente seus grupos colaborativos. Por outro lado, impus os grupos da classe 2, para obter grupos iguais em status (portanto, impus um grupo de quatro alunos com pouca escolaridade e pouco envolvimento, porém com boa capacidade de raciocínio, enquanto outro se formou espontaneamente um grupo de quatro mulheres chefes de classe). Em todos os casos, a 
organização interna dos grupos foi deixada à liberdade dos alunos, não tendo intervindo (ou muito pouco) durante a sessão.

Os alunos do grupo de controle trabalharam em duplas, nos mesmos documentos, mas com perguntas orientadas para dar-lhes tempo para processar todos os documentos. Teria sido interessante fornecer aos alunos uma ferramenta digital de escrita colaborativa, como o software Framapad. Isso não foi feito por motivos materiais (o Framapad não está acessível nos computadores da universidade, a falta de tempo não permitiu resolver este problema técnico no âmbito desta tese).

\section{Avaliação de treinamento cooperativo e colaborativo.}

\section{Formativo}

Na sessão seguinte, foi realizada uma avaliação formativa destas duas primeiras sessões, sem aviso prévio aos alunos, a fim de testar a sua compreensão nesta fase das atividades realizadas de forma cooperativa e clássica, evitando avaliar uma aprendizagem ou uma releitura de atividades que poderiam ter retornado itens da memória. A forma de avaliação escolhida foi um questionário de múltipla escolha, que permite aos alunos avaliar individualmente sua compreensão e não suas habilidades de escrita, ao mesmo tempo que elimina o viés de correção associado à avaliação. Cada uma das dez questões é pontuada com 1 ponto. As perguntas podem ter várias respostas corretas ( 0,5 pontos ou resposta correta). Qualquer resposta falsa é penalizada com uma redução de 0,5 pontos. O que mais, Foram coletados todos os relatórios do trabalho prático (diagramas e texto explicativo da pressão arterial, diagrama e equilíbrio do sistema músculo-articular, documento sumário de doping). Esses documentos permitem uma avaliação formativa do trabalho coletivo a ser realizado. 
Tabela 7:

Conteúdo da avaliação somativa realizada no final das três práticas.

\begin{tabular}{|c|c|c|c|c|}
\hline Exercício & Tema & Natureza da questão & $\begin{array}{c}\text { Habilidade } \\
\text { avaliado }\end{array}$ & Escala \\
\hline 1 & Pressão arterial & $\begin{array}{l}\text { Restituição de conhecimento: } \\
\text { - Complete um diagrama funcional. } \\
\text { - Escreva um texto sobre a regulação nervosa } \\
\text { da pressão arterial em caso de queda de } \\
\text { pressão. }\end{array}$ & $\begin{array}{l}\text { Conheça, } \\
\text { comunique- } \\
\text { se }\end{array}$ & 7 pts. \\
\hline 2 & Doping & $\begin{array}{l}\text { Questionários sobre os principais conceitos } \\
\text { construídos durante o trabalho prático (modo } \\
\text { de atuação do EPO, aspectos legais e aspectos } \\
\text { socioeconômicos do doping) }\end{array}$ & $\begin{array}{c}\text { Saber, } \\
\text { Raciocinar }\end{array}$ & 3 pts. \\
\hline 3 & $\begin{array}{l}\text { Diagrama e sistema } \\
\text { médico-muscular) } \\
\text { relacionado a uma } \\
\text { articulação }\end{array}$ & $\begin{array}{l}\text { Síntese de documentos (texto, imagens, } \\
\text { acidente do sistema músculo-articular } \\
\text { (análise dos efeitos de ruptura do tendão de } \\
\text { Aquiles). }\end{array}$ & $\begin{array}{l}\text { Saber } \\
\text { informar }\end{array}$ & 7 pts. \\
\hline 4 & Pressão arterial & $\begin{array}{l}\text { Análise de experimentos regulatórios (efeito } \\
\text { de oclusão arterial e diclusão da artéria } \\
\text { carótida) }\end{array}$ & $\begin{array}{c}\text { Razão e } \\
\text { comunicação }\end{array}$ & 3 pts. \\
\hline
\end{tabular}

Garavit, J. 2021

\section{Somativa}

Terminada a sessão de revisão da unidade curricular, procede-se a uma avaliação sumativa para testar a aquisição individual de conhecimentos sobre os dois temas abordados. A Tabela 7 abaixo detalha o conteúdo e a escala dessa avaliação.

Utiliza-se uma escala móvel para pontuar o DS, da nossa responsabilidade, para harmonizar a nossa forma de corrigir as cópias.

Os resultados serão analisados primeiro de um ângulo quantitativo e, em seguida, de um ângulo qualitativo.

\section{Quantitativo}

Os dados quantitativos vêm de pontuações do questionário (avaliação formativa) e tarefas supervisionadas (DS = ES, avaliação somativa).

Para todas as aulas, a média das notas obtidas no questionário é de 5,6 / 10, variando de 2 a 10, enquanto a média da tarefa é de 11,86 / 20, variando de 4 a 18,5. A Tabela 8 a seguir mostra as anotações por subgrupo, aqueles que realizaram a sessão de pressão arterial no modo cooperativo (grupos A) e aqueles que realizaram a sessão sobre o sistema musculoesquelético no modo cooperativo (grupo B). Cada um desses grupos realizou a outra sessão em pares, clássica. Observa-se uma diferença inferior a 0,20 pontos entre os grupos. 
Tabela 8.

Pontuação dos grupos A e B.

\begin{tabular}{|c|c|c|}
\hline & $\begin{array}{c}\text { Pontuação do } \\
\text { questionário (10) }\end{array}$ & $\begin{array}{c}\text { Pontuação do questionário } \\
(\mathbf{2 0})\end{array}$ \\
\hline Grupos A - cooperativa & 5,53 & 11,94 \\
\hline $\begin{array}{c}\text { Grupos B - cooperativa no sistema } \\
\text { musculoesquelético }\end{array}$ & 5,69 & 11,79 \\
\hline Total & $\mathbf{5 , 6 1}$ & $\mathbf{1 1 , 8 6}$ \\
\hline
\end{tabular}

Garavit, J. 2021

\section{Shunts de deliberação de pressão arterial}

A Tabela 9 a seguir detalha os resultados relacionados à aquisição de noções sobre o circuito de regulação da pressão arterial. Surpreendentemente, os grupos que trabalharam cooperativamente nesse conceito tiveram menos sucesso do que os outros grupos, a parte do questionário dedicada à pressão arterial, bem como o exercício de raciocínio do SD dedicado a esse conceito. No entanto, deve-se observar que as diferenças nas notas são bastante pequenas (-0,20 a -0,15 pontos, ou 6 a $13 \%$ da nota média) e, portanto, podem ser consideradas não representativas. Pelo contrário, a parte de recuperar conhecimentos sobre este mesmo tema teve mais sucesso para quem trabalhava em cooperação $(+0,25$ pontos em média ou $6 \%$ da nota média). Aqui, novamente, as margens de pontuação são pequenas.

\section{Tabela 9}

Resultados das avaliações formativa e somativa - pressão arterial.

\begin{tabular}{|c|c|c|c|}
\hline & $\begin{array}{c}\text { Questionário } \\
\text { pressão arterial } \\
6 \text { pontos }\end{array}$ & $\begin{array}{c}\text { Conhecimento } \\
7 \text { pontos }\end{array}$ & $\begin{array}{c}\text { Raciocínio } \\
3 \text { pontos }\end{array}$ \\
\hline Grupos cooperativos & 2,95 & 4,52 & 1.09 \\
\hline Grupos Tradicionais & 3,15 & 4,27 & 1,24 \\
\hline Total & $\mathbf{3 , 0 6}$ & $\mathbf{4 , 3 9}$ & $\mathbf{1 , 1 6}$ \\
\hline
\end{tabular}

Garavit, J. 2021

\section{Shunts de deliberação musculoesquelética}

De acordo com o esperado desta vez, os alunos que realizaram a sessão sobre o sistema musculoesquelético no modo cooperativo responderam um pouco melhor às questões do questionário e tarefas, relacionadas à noção do sistema musculoesquelético. 
Tabela 10:

Avaliações formativas e somativas - músculo esquelético

\begin{tabular}{|c|c|c|}
\hline & $\begin{array}{c}\text { Número médio de problemas do } \\
\text { sistema muscular articular (em 4 } \\
\text { pontos) }\end{array}$ & $\begin{array}{c}\text { DS - Raciocínio Médio baseado } \\
\text { em sistemas músculo- } \\
\text { articulares (7 pontos) }\end{array}$ \\
\hline Grupo Cooperativo & 2,66 & 4,23 \\
\hline Grupo tradicional & 2,55 & 4,17 \\
\hline Total & 2,61 & 4,20 \\
\hline
\end{tabular}

Garavit, J. 2021

\section{Derivações da deliberação de doping (treinamento colaborativo)}

Durante a avaliação somativa foram feitas três perguntas sobre o doping, os grupos que lidaram com o tema de forma colaborativa obtêm uma pontuação média de 2,05 pontos / 3, enquanto os demais obtêm um pouco menos: 1,98 pontos / 3. Aqui de novo, o as diferenças devem ser analisadas com medida.

\section{Dados quantitativos}

Os dados relacionados à pressão arterial (questionário e DS) foram combinados para fornecer uma pontuação geral da pressão arterial. O mesmo foi feito com os dados do sistema músculo-articular. O objetivo de somar as diferentes pontuações obtidas é gerar resultados mais consistentes e representativos. A Tabela 11 a seguir mostra os resultados obtidos a seguir: média e desvio padrão das notas obtidas em toda as questões relacionadas a um conceito (questões do questionário e avaliação somativa).

Tabela 11:

Resultados gerais das duas sessões de treinamento cooperativo

\begin{tabular}{|c|c|c|c|c|}
\hline & \multicolumn{2}{|c|}{ Pressão arterial } & \multicolumn{2}{c|}{ Músculo-articular } \\
\cline { 2 - 5 } & $\begin{array}{c}\text { Total de pontos na } \\
\text { pressão arterial (de 16 } \\
\text { pontos) }\end{array}$ & $\begin{array}{c}\text { Dotal de pontos em } \\
\text { Gentil } \\
\text { questões do sistema de } \\
\text { diferença músculo- } \\
\text { articular (de 11 pontos) }\end{array}$ & $\begin{array}{c}\text { Diferença } \\
\text { Gentil }\end{array}$ \\
\hline $\begin{array}{c}\text { Grupos cooperativos } \\
\text { A na pressão arterial }\end{array}$ & 8,53 & 2,46 & 6,74 & 1,82 \\
\hline $\begin{array}{c}\text { Grupos B - } \\
\text { cooperativa no sistema } \\
\text { musculoesquelético }\end{array}$ & 8,53 & 2,83 & 6,73 & 1,65 \\
\hline Total & $\mathbf{8 , 5 3}$ & $\mathbf{2 , 6 3}$ & $\mathbf{6 , 7 4}$ & $\mathbf{1 , 7 3}$ \\
\hline
\end{tabular}

Garavit, J. 2021 
Percebe-se que as médias são semelhantes entre os dois tipos de turmas, ou seja, entre os alunos que trabalharam cooperativamente e os demais. Portanto, essas notas não apresentam nenhuma vantagem significativa para um ou outro dos métodos de trabalho. No entanto, observamos que o desvio padrão das avaliações é menor para os grupos que trabalharam cooperativamente do que para os grupos que tradicionalmente trabalharam em pares. Além disso, as notas mais baixas foram obtidas por alunos que trabalharam de forma clássica. Desta vez as diferenças são significativas: $+0,5$ pontos a favor dos alunos mais fracos no modo cooperativo em relação aos do modo clássico para pressão arterial $(3,25$ contra 2,75 , ou seja, $+18 \%$ de diferença); e uma diferença de +1 . 5 pontos para alunos que trabalharam cooperativamente no sistema músculo-articular em comparação com os demais (4 versus 2,5, ou seja, $+60 \%$ de diferença). A Figura 1 abaixo ilustra essa lacuna.

\section{Derivações qualitativas.}

\section{Deliberações de treinamento cooperativo}

Processo de modo cooperativo: A sessão sobre regulação da pressão arterial começou com uma introdução de cerca de quinze minutos sobre os conceitos de pressão arterial, valor regulado e um lembrete sobre o funcionamento de um circuito nervoso. Eu constituo os grupos de alunos, então cada dupla de especialistas realiza suas simulações de experiência no software Regularxa. Os alunos lutam para entender os experimentos, incluindo o papel dos barorreceptores do seio carotídeo. Os especialistas no tópico 2 (papel dos nervos simpático e parassimpático) terminam mais rápido do que os do tópico 1. Durante a fase teórica, os alunos têm dificuldade em definir seus respectivos papéis na produção esperada e encontram dificuldades cognitivas relacionadas com os conceitos abordados.

Comportamento do aluno: Vejo um investimento desigual dos pares. Dois grupos a que pertencem (4 alunos) estão na mesma configuração, com um parceiro excelente e um parceiro pouco assíduo: os bons alunos frustram-se e os menos assíduos confiam nos outros.

Resultados: Durante a primeira sessão que conduzo numa cooperativa, com a $6^{\text {a }}$ turma, os alunos não têm tempo para terminar o diagrama e o texto de síntese. Na segunda sessão, com a aula 2, eles conseguem me passar o resumo no final da sessão. Muitos grupos esquecem de mencionar o papel do tronco cerebral ao escrever um texto que explica como funciona o ciclo de regulação. Em geral, eles entenderam o papel dos outros atores do ciclo. Para todos os alunos, a noção de regulação da pressão arterial permanece complexa, assim como a análise de experiências. $\mathrm{O}$ curso da sessão no modo clássico é bastante próximo ao descrito acima (introdução, ativação). Também gasto muito para ajudar os diferentes casais que se deparam com essa ideia. Poucos casais conseguiram terminar seu relatório em sala de aula. 


\section{Deliberação do sistema músculo-articular}

Para a sessão de treinamento cooperativo no sistema músculo-articular, a organização que funcionou bem é onde o treinamento é dividido em grupos de quatro alunos da seguinte forma:

- Um casal disseca e apresenta os resultados da dissecção ao parceiro.

- Um casal trabalha em um documento.

A composição das turmas é imposta pelo professor para formar turmas de nível homogêneo. Grupos de especialistas se formam espontaneamente ao longo da aula: os que trabalham nos documentos se reúnem e discutem entre si, principalmente quando estão ocupados ajudando os que dissecam (tarefa mais difícil e mais longa). Os grupos cooperam bem. O nível de som é limitado durante a partilha, as trocas parecem frutíferas em vários grupos. No entanto, existe uma dificuldade em produzir relatórios verdadeiramente abrangentes.

\section{Deliberação de treinamento colaborativo}

A sessão começa com a projeção de um spot da Agência Mundial Antidoping Diga não ao doping, então o conceito de doping é definido coletivamente. Depois de anunciar as instruções simples, os grupos se formaram (livremente na aula $2^{\circ} 6$ e impostos na aula $2^{\circ}$ 2) e rapidamente começaram a trabalhar. As sessões de trabalho colaborativo desenvolveramse em total autonomia. A grande maioria dos grupos funcionou de forma semelhante: abordaram espontaneamente o modo cooperativo com uma distribuição de tarefas, cada aluno tratou de um dos quatro tópicos, a seguir a consolidação das diferentes produções individuais no final da sessão durante um tipo de fase de treinamento.

Outros alunos dividiram os tópicos em pares e juntos escrevem duas partes, para a produção final, alguns grupos apenas compilaram as produções individuais (os que trabalharam em computador em particular), outros escreveram um resumo juntos. Alguns raros grupos realmente trabalharam em colaboração: dois grupos de quatro meninas em particular. Foram explicados os diferentes documentos que analisaram individualmente, definindo em conjunto a forma e o nível de detalhamento da produção a devolver, bem como o tempo atribuído a cada tarefa. Um desses grupos escreveu o resumo juntos (os quatro), de forma manuscrita. 


\section{Tabela 12}

\section{Estratégias implementadas durante a sessão de treinamento colaborativo}

\begin{tabular}{|c|c|c|c|}
\hline Classe & Grupo & Comportamento & Produção final \\
\hline \multirow{4}{*}{206} & $\begin{array}{l}\text { Grupo } 1 \\
\text { Aluno } 1 \\
\text { Aluno } 2 \\
\text { Aluno } 3 \\
\text { Aluno } 4\end{array}$ & $\begin{array}{l}\text { Cada um trabalha por conta própria, faz anotações e depois } \\
\text { as monta. Eles usam a Internet para encontrar a definição de } \\
\text { palavras mal compreendidas. O aluno } 4 \text { explica a teoria dos } \\
\text { jogos para os outros. O aluno } 3 \text { está relutante em agir, não } \\
\text { quero, não consigo ler esta tabela. Eles não dão para se } \\
\text { organizar coletivamente. }\end{array}$ & $\begin{array}{l}\text { Texto sintético, mas } \\
\text { completo, escrito em } \\
\text { comum, em } \\
\text { processador de texto }\end{array}$ \\
\hline & $\begin{array}{l}\text { Grupo 2 } \\
\text { Aluno } 5 \\
\text { Aluno } 6 \\
\end{array}$ & $\begin{array}{l}\text { Aluno } 6 \text { Acho que devemos destacar as informações } \\
\text { importantes, distribuir os documentos, em seguida, ler seu } \\
\text { documento individual e, em seguida, apresentá-lo. }\end{array}$ & $\begin{array}{l}\text { Síntese manuscrita } \\
\text { escrita por quatro, na } \\
\text { forma de ensaio. }\end{array}$ \\
\hline & $\begin{array}{l}\text { Grupo } \\
\text { número } 3 \\
\text { Aluno } 7 \\
\text { Aluno } 8 \\
\text { Aluno } 9 \\
\text { Aluno } 10\end{array}$ & $\begin{array}{l}\text { Eles foram organizados em duas duplas, cada dupla } \\
\text { tratando de dois tópicos e garantindo a escrita em } \\
\text { processador de texto. }\end{array}$ & $\begin{array}{l}\text { Consolidação das } \\
\text { produções de cada } \\
\text { binômio. } \\
\begin{array}{l}\text { Apresentação em } \\
\text { power point completo }\end{array}\end{array}$ \\
\hline & $\begin{array}{l}\text { Grupo } 4 \\
\text { Aluno } 11 \\
\text { Aluno } 12 \\
\text { Aluno } 13 \\
\text { Aluno } 14\end{array}$ & $\begin{array}{l}\text { Eles dividem o trabalho por assunto. O aluno } 11 \text { trabalha } \\
\text { sozinho em um tópico e em PowerPoint. Os outros } 3 \\
\text { trabalhando, em processamento de texto. Mas eles mostram } \\
\text { muita falta de coordenação. }\end{array}$ & $\begin{array}{l}\text { Síntese em } \\
\text { processador de texto. }\end{array}$ \\
\hline \multirow{4}{*}{$2^{\circ} 2$} & $\begin{array}{l}\text { Grupo } 1 \\
\text { Aluno } 15 \\
\text { Aluno } 16 \\
\text { Aluno } 17 \\
\text { Aluno } 18\end{array}$ & $\begin{array}{l}\text { Eles disputam a composição (imposta) dos grupos: Não é } \\
\text { justo, há empate. No início da sessão, eles são barulhentos, } \\
\text { brincalhões e demoram a chegar ao trabalho. Algumas } \\
\text { tensões aparecem à medida que a sessão avança, mas não } \\
\text { sua produção. Aluno } 15 \text { e Aluno } 18 \\
\text { eles eventualmente chegam a um computador, cada um por } \\
\text { sua própria conta. Os outros trabalham juntos no papel. }\end{array}$ & $\begin{array}{l}\text { Aluno } 17 \quad \text { É } \\
\text { responsável por } \\
\text { coordenar o trabalho } \\
\text { ao final, inserindo os } \\
\text { textos impressos do } \\
\text { Aluno } 15 \text { e do Aluno } \\
18 \text { na síntese à mão. }\end{array}$ \\
\hline & $\begin{array}{l}\text { Grupo } 2 \\
\text { Aluno } 19 \\
\text { Aluno } 20 \\
\text { Aluno } 21 \\
\text { Aluno } 22\end{array}$ & $\begin{array}{l}\text { Eles explicam os documentos uns aos outros, organizam- } \\
\text { nos (definem a duração por documento, o nível de detalhe) } \\
\text { e depois dividem para escrever o trabalho } 2 \text { a } 2 \text { no } \\
\text { computador. }\end{array}$ & $\begin{array}{l}\text { Produção fornecida } \\
\text { em } \\
2 \text { folhas separadas, } \\
\text { escrito no } \\
\text { computador. }\end{array}$ \\
\hline & $\begin{array}{l}\text { Grupo } \\
\text { número } 3 \\
\text { Aluno } 23 \\
\text { Aluno } 24 \\
\text { Aluno } 25\end{array}$ & $\begin{array}{l}\text { Digitando juntos no computador, eles explicam os } \\
\text { documentos uns aos outros, mesmo que o Aluno } 25 \text { pareça } \\
\text { um pouco fora do caminho. }\end{array}$ & $\begin{array}{l}\text { Síntese de } \\
\text { documentos } \\
\text { em processamento de } \\
\text { texto. }\end{array}$ \\
\hline & $\begin{array}{l}\text { Grupo } 4 \\
\text { Aluno } 26 \\
\text { Aluno } 27 \\
\text { Aluno } 28 \\
\text { Aluno } 29\end{array}$ & $\begin{array}{l}\text { Trabalhe em paz. Todo mundo lê seu tópico. O aluno } 28 \text { é } \\
\text { o responsável pela formatação do resumo, redigido em } \\
\text { processador de texto e ditado pelos } 4 \text { integrantes do grupo. }\end{array}$ & $\begin{array}{l}\text { Organização das } \\
\text { evidências e tudo em } \\
\text { uma ordem imposta } \\
\text { por eles de forma } \\
\text { hierárquica. }\end{array}$ \\
\hline
\end{tabular}

Garavit, J. 2021 
Os métodos de treinamento colaborativo nesta sessão foram muito populares entre os alunos, que estavam muito envolvidos e produziram resumos bastante abrangentes sobre doping. No entanto, não houve realmente nenhum debate interno real dentro dos grupos sobre a questão do doping, de assumir uma posição comprometida. Portanto, os grupos de alunos que trabalharam em duplas clássicas (grupos B das turmas 2 e 6 do segundo ano) apresentaram menos autonomia do que os que trabalharam de forma colaborativa. $\mathrm{O}$ conteúdo da sua síntese é, no entanto, muito abrangente e cobre todos os quatro aspectos do tópico, conforme solicitado.

\section{Re contextualização}

Este estudo teve como objetivo demonstrar que determinados métodos de trabalho em grupo são mais eficazes do que a aprendizagem tradicional. As hipóteses adotadas postulavam que o treinamento cooperativo empoderaria os alunos e melhor fixaria o aprendizado, enquanto o treinamento colaborativo promoveria o avanço da liberdade e da corrente crítica, favorecendo a aquisição de competências. Para testar a validade dessas hipóteses, duas sessões de trabalho prático cooperativo e, em seguida, uma sessão de trabalho prático colaborativo foram estabelecidas em três classes do segundo ano de acordo com os princípios da pedagogia experimental. Para cada aula, um grupo médio trabalha em modo cooperativo ou colaborativo, e o outro grupo, testemunha, trabalha em modo clássico (trabalho em pares).

\section{Vinculando com exames preliminares}

Tendo em conta as notas obtidas no questionário e a avaliação somativa dos diferentes grupos, não vemos qualquer vantagem importante ao nível da aquisição de conhecimentos proporcionada pela modalidade de formação cooperativa ou colaborativa. Na verdade, as discrepâncias nas pontuações médias não são significativas entre os grupos de teste e os grupos de controle (diferenças de aproximadamente 0,15 pontos, o que pode ser devido a um efeito corretivo da avaliação somativa: de uma cópia para outra e de um revisor para outro, nem sempre avaliamos exatamente a mesma coisa). No entanto, o trabalho cooperativo reduz os desvios padrão e melhora as pontuações mais baixas (desta vez com melhorias significativas de 18 a $60 \%$ das pontuações mais baixas).

Em termos qualitativos, o desenvolvimento da autonomia do aluno foi plenamente confirmado no quadro da formação prática e colaborativa, uma vez que não intervim no trabalho de equipa durante estas sessões, salvo por algumas indicações materiais (acesso à impressora, etc.) . Este não foi o caso com o uso do pensamento crítico. Os documentos oferecidos aos alunos. Os hábitos de trabalho dos alunos, bem como o tempo limitado para a 
realização da síntese, não permitiram que os alunos entrassem em discussões reais. Eles se concentraram em produzir um documento que seria devolvido ao final da sessão.

O envolvimento e empoderamento dos alunos no contexto do trabalho cooperativo era variável e refletia o temperamento habitual dos alunos (que não mudaram de atitude durante estes primeiros laboratórios cooperativos). Essas diferenças entre os resultados observados e esperados podem ser explicadas por vários aspectos da implementação das sessões:

A deliberação dos conteúdos abrangidos: $\mathrm{Na}$ pressão arterial, os alunos foram convidados a analisar experimentos simulados em um computador. Os alunos de cada grupo não contribuíram com nenhuma experiência real relacionada com o trabalho a realizar, o que limitou as respectivas contribuições durante a fase de congresso (a sua possível experiência no domínio do software de escritório não foi suficiente neste sentido. A análise científica do simulações).

A natureza dos grupos: o critério da heterogeneidade do grupo para o trabalho cooperativo teria beneficiado de ser mais bem analisado (os grupos foram formados diretamente durante as sessões, e condicionados pelo plano de aula usual, que não garante heterogeneidade em termos de gênero, escolaridade, etc., necessária trabalho cooperativo, conforme mencionado na literatura).

A fase de especialista em sessões de treinamento cooperativo: Cada grupo de especialistas era simplesmente composto de um par (o grupo de membros inicial foi dividido em duas áreas de especialização, mas sem reagrupamento com especialistas de outros grupos de membros) Membros do mesmo grupo de base, portanto, não trabalharam com especialistas de outros grupos de base. Isso limitou as trocas e confrontos de pontos de vista durante essa fase e, portanto, o escopo das aquisições.

A deliberação das metodologias para o grupo de controle: os grupos de controle trabalharam em duplas, o que já pode ser considerado um trabalho de grupo. Na literatura, parece que a eficácia dos modos cooperativo ou colaborativo é avaliada com referência ao trabalho individual. Teria sido necessário impor um trabalho estritamente individual aos grupos de controle e recorrer aos mesmos métodos de avaliação usados na literatura para aproximar os resultados publicados.

\section{Termos e demarcações}

Apesar de ter validado certas hipóteses na literatura, este capítulo apresenta uma série de limitações e vieses. Assim, como pode ser entendido a partir de Philippe Meirieu, a divisão em horas letivas dificulta muito a prática do grupo; Trancar o professor em uma determinada 
sala em um tempo muito curto o obriga, em grande medida, a usar apenas representações já abstratas e a buscar apenas a assimilação individual simples (Meirieu, 2010a). Embora este estudo nos permitisse praticar o trabalho em grupo, era ambicioso querer abordar conceitos tão complexos como a regulação nervosa da pressão arterial ou abordar todos os problemas de doping em uma única sessão de 1 h25. Isso pode ter alterado a compreensão desses conceitos por alguns alunos.

Quanto ao desenvolvimento das sessões de forma cooperativa, teria sido conveniente prepará-lo melhor, com antecedência ao longo do ano, lembrando no início da sessão a importância do envolvimento de cada um para o sucesso de todos. Um período de experimentação superior às três sessões realizadas teria tornado os resultados do estudo mais fiáveis, até porque estes novos métodos de trabalho requerem novos comportamentos por parte dos alunos, que demoram a estabelecer-se.

Além disso, minha falta de experiência pode ter sido um viés durante as sessões. Tendo implementado essas sessões pela primeira vez durante o estudo, meu comportamento certamente influenciou os resultados observados (clareza de instruções e explicações a serem refinadas, etc.).

Por fim, no que diz respeito à análise dos resultados, teria sido interessante fazer um maior uso dos relatórios de trabalho prático elaborados pelos alunos e analisar o seu nível de compreensão em cada etapa (¿cómo analisou o papel de cada ator na alça de regulação da pressão arterial? Eles distinguiram claramente o papel dos barorreceptores nervosos de Hering durante os experimentos de ligadura da artéria carótida? Isso teria permitido que suas aquisições progressivas fossem avaliadas à medida que a sequência progredia e para prosseguir com os possíveis remédios se fosse necessário antes da avaliação somativa .

\section{Perspectiva.}

\section{Melhorias para integrar no curso das sessões}

Para estimar o valor agregado do treinamento cooperativo ou colaborativo de forma mais próxima ao da literatura, um novo estudo poderia comparar a eficácia do trabalho em grupo com a do trabalho individual, exigindo que os alunos trabalhassem sozinhos em grupos de controle.

Nas sessões de trabalho cooperativo, cada membro do grupo de base deve poder escolher o tema a ser investigado, entre os temas predefinidos pelo docente. Essa sensação de liberdade que é conferida aos alunos é uma fonte de motivação para o envolvimento, de acordo com o fenômeno da matrícula definido pela psicologia social. $\mathrm{O}$ aluno tem a 
impressão de não ser totalmente obrigado a obedecer a uma instrução imposta. Tem a impressão de poder escolher a sua atividade, embora o grau de liberdade que lhe resta seja mínimo, o que lhe permite acentuar o seu envolvimento na realização da tarefa e, portanto, facilita a aprendizagem.

Portanto, teria sido interessante dedicar duas sessões ao treinamento colaborativo sobre doping. Isso teria permitido que os alunos fossem livres e independentes em uma fase de coleta de informações, propício para uma colaboração real, em vez de fornecer-lhes documentos selecionados pelo professor. Além disso, o tempo extra poderia ter permitido uma perspectiva mais importante sobre este assunto complexo, despertando uma mente crítica que os alunos lutaram para desenvolver durante esta sessão única. Além disso, o uso de software de edição de texto online colaborativo do tipo Framapad provavelmente teria permitido uma fase de co-escrita que ocorreu apenas em poucos grupos, com os outros grupos tendo tendência a compilar textos escritos de forma independente entre si.

\section{Ferramentas: grades de reflexão}

Como sugere Meirieu (2010b), também seria necessário refinar a análise qualitativa do trabalho em grupo utilizando uma grade de observação em que os tempos de conversação, a distribuição de tarefas e as capturas, responsabilidades são registrados, ou que se baseia em uma grade mais especificamente dedicado à formação colaborativa, através de uma tipologia de comportamentos e indicadores predefinidos.

Essas sessões de treinamento colaborativo e cooperativo foram instrutivas. Os alunos se envolveram e encontraram prazer nisso. Esses são métodos de aprendizado nos quais reinvestirei no futuro, enquanto faço certas modificações para criar condições mais propícias para otimizar o aprendizado.

\section{conclusão}

Entre as diferentes correntes educacionais, o construtivismo social é aquele que dá lugar mais importante à intervenção de outrem no desenvolvimento do conhecimento. Assim, o conflito sócio-cognitivo permite ao aluno que trabalha em grupo descentrar e dar um passo atrás em relação às suas concepções iniciais, obrigando-o a argumentar perspetivas adicionais dos membros do grupo, isto permite ao aluno construir o seu próprio conhecimento.

$\mathrm{O}$ estudo aqui realizado em três classes gerais insere-se nesta corrente de pensamento. Pretendeu-se mostrar que a formação cooperativa e a formação colaborativa são métodos de trabalho que permitem adquirir melhores conhecimentos para os primeiros e progredir através do desenvolvimento da autonomia e do pensamento crítico para os segundos. 
Este estudo demonstrou ampla autonomia em um ambiente colaborativo, os resultados são menos convincentes do ponto de vista quantitativo. Os dados do estudo simplesmente confirmam que esses métodos de aprendizagem levam a melhores resultados para os alunos mais fracos e reduzem o desvio padrão das notas obtidas. O escopo do estudo é certamente limitado por diversos vieses relacionados às modalidades de sua implementação. Um novo estudo permitir-nos-ia ir mais longe nestes resultados, sujeito a uma adaptação do rumo das sessões e dos meios didácticos utilizados. Tendo em vista os benefícios comportamentais e comunicacionais obtidos, esses são definitivamente métodos de aprendizagem que usarei novamente ao longo da minha carreira. 


\section{Referências}

Baudrit A. (2005) Aprendizagem cooperativa. Origens e desenvolvimentos de um método de ensino. De Boeck, setembro de 2005. Developing Pedagogies.

Baudrit A. (2005a) Aprendizagem colaborativa. Mais do que um método coletivo? De Boeck, Mars 2007. (Pedagogias em desenvolvimento).

Baudrit A. (2005b) Formação de professores em métodos de aprendizagem cooperativa: perspectivas internacionais, Savoirs, 2007/2 $\mathrm{n}^{\circ} 14$.

Baudrit A. (2005c) Aprendizagem cooperativa / Aprendizagem colaborativa: do comparativismo convencional ao comparativismo crítico. Ciências da Educação: para a nova era, 2007/1 Vol. 40.

Baudrit A. (2005 Aprendizagem colaborativa: visões distantes em ambos os lados do Atlântico? Carrefours de in education, 2009/1 n ${ }^{\circ} 27$.

Centro Educativo. (2004) Centro de Educação Carrefour. Educação 2.0.

David C. (2015) Behaviorismo vs conectivismo: a contribuição dos ambientes de computação para a aprendizagem humana na França.

Kozanitis A. (2005) Escola Politécnica de Montreal. As principais correntes teóricas do ensino e da aprendizagem: um olhar histórico. Dezembro de 2005.

Meirieu P. (2010) Itinerário de pedagogias de grupo. Aprendizagem em grupo - 1. P25. Social Chronicles, fevereiro de 2010.

Meirieu P. (2010b) Ferramentas para aprendizagem em grupo. Aprendizagem em grupo - 2. Crônicas Sociais, fevereiro de 2010.

Peeters L. (2005) Métodos de ensino e aprendizagem em grupo. De Boeck, 2005. (Ciências da Educação).

Sumputh M., Fourcade F., (2013) Audacious complex cooperative pedagogy. Da escola à universidade. Social Chronicle, janeiro de 2013. 